\section{Programa de Género, Sociedad y Universidad: un laboratorio de igualdad que cumple una década}

Ana Fiol

Integrante del equipo del Programa de Género,

Sociedad y Universidad. Universidad Nacional del Litoral.

\section{Nos presentamos}

El Programa Género, Sociedad y Universidad, que fuera creado en el 2002 en el marco de la Secretaría de Extensión de la Universidad Nacional del Litoral, cumple diez años de labor política y epistemológica articulando docencia, extensión e investigación en las fronteras disciplinarias e institucionales de las grandes transformaciones, luchas e interrogaciones de nuestra época. La creación del Programa responde a la preocupación de la Universidad por las deficiencias democráticas que el sistema de sexo-género ${ }^{1}$ asegura y reproduce dentro y fuera de nuestra casa de estudios. De este modo, la tradición reformista e ilustrada de nuestra Universidad se reactualiza y se compromete con la lucha de las mujeres por el ejercicio pleno de sus derechos y, de esta manera, con la efectiva universalización de la ciudadanía.

Aceptando el desafío, en el año 2002 la Universidad implementó mediante Resolución del Consejo Superior $n^{\circ}$ 101/02 el Programa de Género. Desde hace diez años, este espacio académico se presenta como un ámbito de formación en género y feminismo, de investigación, docencia y producción de conocimientos y transformaciones en áreas sociales específicas vía la extensión, de articulación sistemática con la sociedad civil, de monitoreo de políticas públicas y de labor de asesoramiento en equidad de género a los Estados municipal y provincial.

El Programa está orgulloso de tener una impronta militante. Por esta razón, son vertebrales las actividades de difusión mediática, las campañas de creación de conciencia y la capacitación de agentes sociales, con el objetivo de visibilizar las problemáticas específicas de las mujeres, difundir sus derechos y las herramientas que permiten su petición y reclamo, y buscar e impulsar los cambios necesarios a través de las múltiples acciones y actividades que posibilita la extensión universitaria. En este contexto, se realizan variadas actividades juntamente con sectores de la educación, legislación, gestión y comunicación.

La construcción de esta década ha sido laboriosa y accidentada, y es por eso que desde el Programa consideramos que tenemos mucho por celebrar: las conquistas, los aciertos, las transferencias de saberes de la academia a la sociedad, y la construcción de
Construir ciudadanía /

Intervenciones líneas de trabajo sólidas y estables, que crecen alrededor de los problemas actuales que nos interpelan.

A continuación, primero, esbozaremos brevemente la historia y características de la/s teoría/s feminista/s. Seguidamente, nos proponemos analizar-relacionar las líneas de trabajo del Programa con un arco de teorías feministas que tiene tres siglos y que se extiende desde la Revolución Francesa hasta los estudios queer. Este ejercicio tiene el propósito de articular prácticas y teorías y mostrar la riqueza conceptual que articula nuestro trabajo y los puntos de antagonismo y desacuerdo, que tan estimulantes nos resultan.

\section{Líneas de trabajo y desarrollos teóricos: de la sociedad paritaria de la igualdad de los sexos a la disolución de los géneros}

Nuestro Programa tiene su base central en la tradición de la teoría crítica feminista, cuya tarea es exponer cómo los "sistemas de sexo-género" históricamente conocidos han participado en la opresión y explotación de las mujeres. Kate Millett (2010) entiende por el sistema sexo-género el modo esencial y material en que la realidad social se organiza y se divide simbólicamente, en función de la diferencia sexual, para establecer una forma de poder ancestral entre varones y mujeres, y por lo tanto formas sexuadas de agencia y de subjetividades.

El feminismo, como toda teoría crítica, es a la vez descriptivo e inevitablemente prescriptivo y, por ende, militante. Es decir que entraña una dimensión ética cuyos orígenes se encuentran en la tradición ilustrada, anudada en torno a las ideas de autonomía, igualdad y solidaridad, las cuales son el producto del lluminismo, la Modernidad y la Revolución Francesa. La historia de la progresiva emancipación de las mujeres comienza con la Declaración de Derechos de la Mujer y la Ciudadana de Olympe de Gouges, publicado en 1791, y que le valiera la guillotina, y con la Vindicación de los Derechos de las Mujeres de Mary Wollstonecraft en 1792. Para la filósofa feminista Amelia Valcárcel, esta lucha por los derechos fue acompañada por una teoría centrada en deslegitimar conceptual, el género hace referen- cia a la matriz heterosexista del poder a través del cual se construyen las identidades individuales, las relaciones sociales y las representaciones simbólicas. Para una discusión completa sobre el paradigma Cf. Metamorphoses. Towards a materialist theory of becoming. Rosi Braidotti, London: Polity Press, 2002, pp. 60 y ss. 





la ideología de la naturaleza diferente y complementaria de los sexos, a la que tan generosamente habían contribuido autores claves de la Modernidad como Rousseau, Locke y Kant. La lucha por la inclusión de las mujeres en la esfera pública y para obtener los derechos civiles fundamentales continúa hasta que, a fines del siglo XIX, surge lo que se conoce como la Primera Ola del Feminismo con el sufragismo como hito más importante, y que comprendía, además del derecho a votar, el derecho al trabajo asalariado (de las mujeres burguesas) y a la educación superior. Es ésta, entonces, la historia de una conquista de derechos que Celia Amorós (2006) ha llamado el ciclo de la vindicación y que hasta aquí buscaba que las mujeres fueran admitidas como sujetos en lo "genéricamente humano". La inauguración de la Segunda Ola por parte del libro seminal de Simone de Beauvoir, El segundo sexo, publicado en 1949, permitió comprender a las mujeres que lo genéricamente humano tenía un subtexto masculino. Como consecuencia, pasamos de la vindicación a la crítica de lo genéricamente humano como androcéntrico. La Tercera Ola de militantes del movimiento de mujeres y de académicas feministas desplazó el centro de las tensiones de lo público a lo privado. Durante doscientos años las mujeres habían luchado por su inclusión en la esfera pública y ahora enfocaban su atención a las formas opresivas que se albergaban en las costumbres, en la estructura familiar, en las relaciones de amor. La Tercera Ola del feminismo, también llamado "feminismo radical" o "de la diferencia sexual" acuñó en los 70 que "lo personal es político" e iluminó formas de discriminación y explotación que habían estado invisibles hasta entonces. Asimismo, supuso la redefinición de las fronteras entre público y privado y la articulación de la diversidad (sexual, étnica, religiosa, etc.). El feminismo contemporáneo está cruzado por las perplejidades y contradicciones del presente. Lo que moviliza buena parte de los desarrollos de la teoría y de la práctica feminista desde los años 80 y 90 está encarnado en nuestras líneas de trabajo, como veremos más adelante, pero primero quisiéramos listar a continuación estas líneas mencionadas:

- Derechos sexuales y derechos reproductivos como derechos humanos.

- Violencia de género.

- Trata y prostitución.

- UNL Igualitaria: políticas universitarias por la igualdad de género.

- Género y medios de comunicación

- Mujer y trabajo.

- Mujeres indígenas.

- Diversidad sexual, ciudadanía y derechos humanos.

- Políticas públicas locales con perspectiva de género.

2) El cuerpo de las mujeres es considerado como un territorio biopolítico por teóricas feministas contemporáneas tan diversas como Marcela Lagarde o Judith Butler. Para Lagarde, "cautiverio" es la categoría

Estas líneas de trabajo son nudos de investigación, acciones estratégicas e intervenciones en territorios institucionales y simbólicos, y de disciplinas teóricas que alimentan la reflexión. Como señalamos más arriba, se fueron gestando apremiadas por la demanda de equidad que existe tanto dentro de la Universidad como en su entorno social y están impregnadas de supuestos teóricos y orientaciones normativas. Requieren de enfoques multidisciplinarios tanto como de rupturas epistemológicas que permiten la crítica sistemática de las disciplinas sociales y naturales desde un punto de vista de género. Fundamentalmente, todas ellas están firmemente asentadas sobre los derechos humanos, es decir que tienen en común que alertan sobre derechos vulnerados, débilmente preservados o directamente ausentes. Esto significa que todas ellas conllevan una tarea persistente para expandir la ciudadanía de las mujeres. El ciclo de la vindicación no ha terminado, por el contrario, se ha ampliado el número de derechos que deben ser asegurados para las mujeres junto con el avance de la democracia y de la igualdad. ¿Qué nuevos derechos reclaman las mujeres en el presente? Y, por otro lado, ¿cómo teoriza el feminismo esta falta/deficiencia de derechos? Comencemos por los derechos sexuales y reproductivos. Éste es un reclamo por la autonomía de las mujeres sobre su propio cuerpo, es decir, sobre la capacidad de tomar decisiones informadas acerca de su vida sexual. Desde la perspectiva feminista, la sexualidad es un campo político de lucha, de dominio, de control y disciplinamiento social, donde los cuerpos de las mujeres —niñas, adolescentes y adultas — son los más vulnerados, sin dejar de lado que sobre los varones también operan mandatos muchas veces difíciles de sobrellevar. La sexualidad, los cuerpos, son territorios políticos donde los límites entre lo público y lo privado se tornan problemáticos y porosos. ¡Lo personal es político! Si la sexualidad atañe sólo al mundo de lo privado, las políticas públicas no podrían ocuparse del tema porque serían relaciones que se dan en el ámbito de lo privado, doméstico, familiar. Si aceptáramos este postulado, la violencia contra las mujeres, el abuso sexual infantil contra niños/as y adolescentes, el sometimiento de las mujeres de todas las edades, serían hechos privados y particulares, aislados, sin posibilidad de intervención y transformación fuera de la esfera privada. El ejercicio de ciudadanía plena empieza en la conquista del primer territorio de ciudadanía que es el propio cuerpo, entendido como cuerpo vivido, sexuado y performativamente construido por el poder. ${ }^{2}$

El segundo territorio a conquistar para la ciudadanía plena de las mujeres es el hogar, y es éste el escenario de la violencia más común y extendida sobre las mujeres, lo que nos lleva a nuestra segunda línea de trabajo. La violencia contra las mujeres está

antropológica que mejor define la condición histórica de las mujeres. Butler asegura que el cuerpo es cons- truido por la repetición ritualizada de reglas, es normativamente constituido en forma performativa por el poder. 
el fundamento mismo de la violencia y el abuso hacia las mujeres en sus hogares se encuentra en estas formas arcaicas y persistentes de poder de los varones

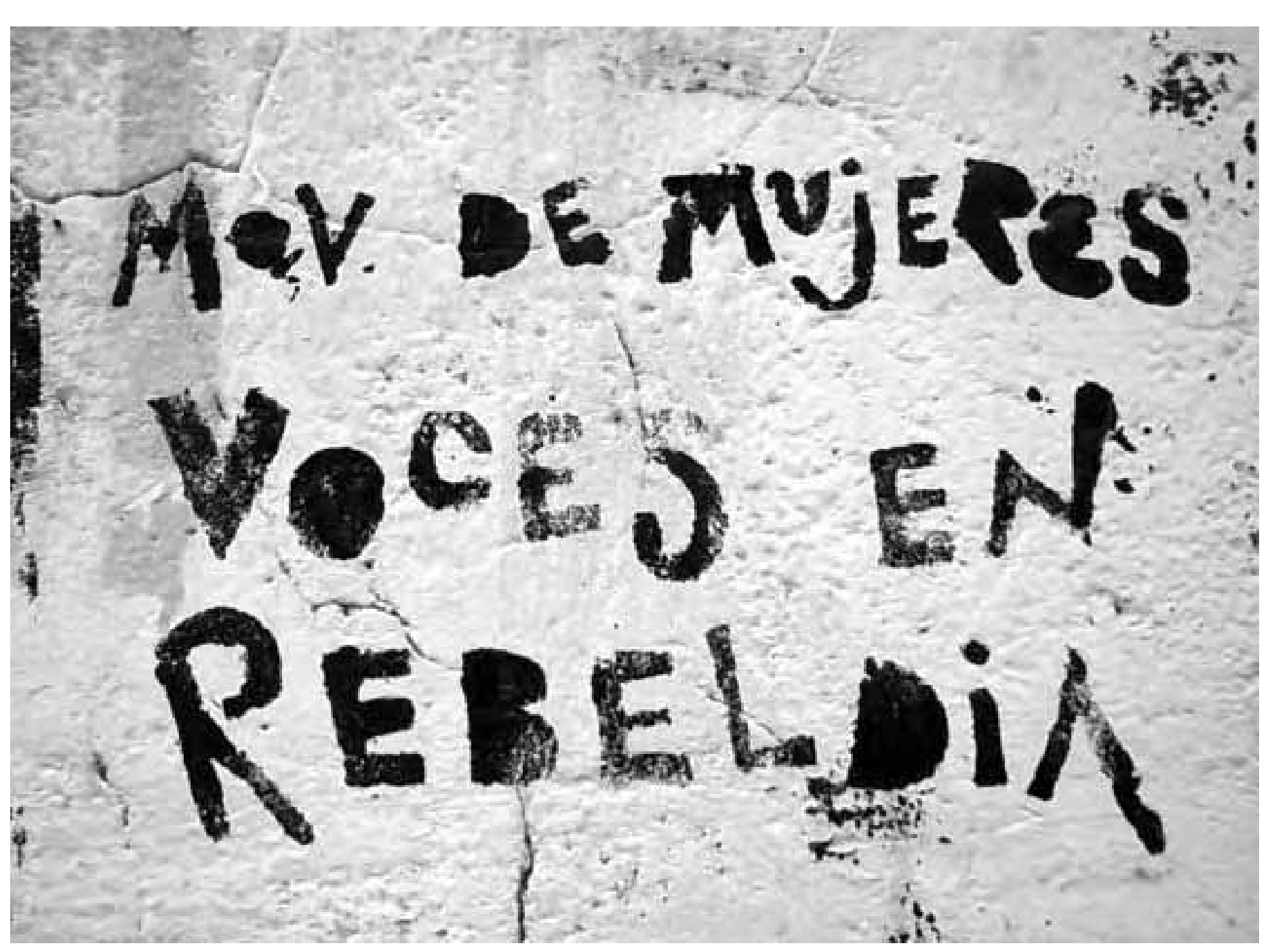


autorizada por la costumbre, sancionada por las religiones y reforzada por una división estricta entre lo público y lo privado. Según la teóloga feminista Isabel Gómez Aceibo, le debemos a todas las religiones la creencia arcaica de que las mujeres son inferiores por naturaleza, por lo cual en el orden natural las mujeres están supeditadas a los varones y a ser madres de sus hijos. Gómez Aceibo afirma que todas las religiones y civilizaciones han confinado a las mujeres a la casa con el fin de asegurar la descendencia. El cristianismo, según la teóloga, ha estado particularmente obsesionado con la castidad femenina y ha confinado a las mujeres a los gineceos y al hogar (Gómez Aceibo, 2003:120).

La famosa frase de Simone de Beauvoir: "no se nace mujer, se llega a serlo" se refiere al destino social que las mujeres traen al nacer y que la socialización se encarga de garantizar: para ser una "Mujer" hay que ser madre, tener virtudes domesticas, quedarse en casa y, si no se puede, tercerizarle el trabajo a otra mujer.

Por supuesto que estas costumbres, creencias y convicciones patriarcales están cambiando. En las sociedades abiertas, las nuevas generaciones de mujeres jóvenes ya no son tan tradicionales y quieren para sí mismas nuevos roles y otro estatus. Sin embargo, el fundamento mismo de la violencia y el abuso hacia las mujeres en sus hogares se encuentra en estas formas arcaicas y persistentes de poder de los varones. Es el derecho garantizado de los varones al cuerpo de las mujeres, como explicara tan brillantemente Carole Pateman en el Contrato sexual, publicado en 1988.

El derecho de los varones sobre el cuerpo femenino, lo cual es el reverso de decir que las mujeres no son dueñas de sus propios cuerpos o son cuerpos disponibles, como se mencionó antes, nos lleva directamente a la siguiente línea de trabajo: la trata y la prostitución. Para Sheila Jeffreys (2011), el tráfico y la prostitución de niñas y mujeres se ha globalizado e industrializado en los últimos veinte años, habiéndose integrado a las economías y a la estructura de empleo de muchos países. La industria del sexo produce ganancias exorbitantes. Es la tercera industria global. En Holanda, donde está legalizada, equivale al $5 \%$ del PBI (año 2009). En China se estima que la industria de la prostitución constituye el $8 \%$ del $\mathrm{PBI}$ y que existen entre 10 y 20 millones de mujeres prostituidas. En Santa Fe hay una conciencia creciente sobre el problema de la trata y la naturalización e invisibilización de la prostitución, y esta línea de trabajo ha contribuido con este fin.

Frente a la pregunta por los derechos vulnerados de las mujeres en situación de prostitución, el feminismo está dividido entre quienes consideran a la prostitución un trabajo legítimo y quienes la consideran una práctica tradicional cultural nociva. ${ }^{3}$ La idea neoliberal del feminismo posmoderno es que la prostitución es un trabajo como cualquier otro y por lo tanto se lo debe regular y cobrarle impuestos. Sectores más radicales del feminismo son "abolicionistas" y sostienen que la prostitución es siempre una violación a los derechos humanos de las mujeres y que es al mismo tiempo causa y consecuencia, esto es, que produce y refuerza la subordinación femenina porque reduce a las mujeres a su vagina. Nuestra Línea Mujer y Trabajo atiende las vulnerabilidades específicas que afectan a las mujeres en los mercados laborales, monitorea la manera en que las crisis y los períodos de cierta bonanza impactan en la capacidad de las mujeres para conseguir empleos, analiza la manera desigual en que se reparten promociones y asensos, y atiende a situaciones de acoso laboral y doble y triple jornada de trabajo.

Fueron las feministas marxistas las que aportaron a nuestra comprensión acerca de la doble explotación de las mujeres por el capitalismo y el patriarcado. Fueron precursoras venerables, como Alexandra Kollontai, quien escribió en 1917 al calor de la organización de las mujeres de la revolución rusa La base social de la cuestión femenina, con cuestionamientos hacia la maternidad, la insatisfacción sexual de las mujeres, además de la doble explotación del mercado, dentro y fuera de la casa. Durante los años 80, las académicas feministas como Heidi Hartman (1979) e Iris Young (1981) comprendieron que patriarcado y capitalismo son dos sistemas autónomos, analíticamente discernibles y distintos en su desarrollo y lo que se discute es cómo ambos sistemas se relacionan entre sí, se apoyan, se refuerzan, o permanecen independientes, cada uno fiel a su propia dinámica. Surge así la teoría del Doble Sistema o del Sistema Dual.

El rasgo que distingue a las feministas liberales de las radicales es la convicción diferenciada acerca de la sexualidad como una condición de la explotación. Para Kathleen Barry (1995), el cuerpo se ha convertido en el terreno de la dominación. El cuerpo del que habla es el de la mujer sexualizada, el modelo pornográfico, el matrimonio y la reducción de todas las mujeres a "cuerpo disponible", que es el último estadio de la dominación patriarcal. El feminismo cultural de los 80 se ha caracterizado por defender una contracultura femenina que contrapone en forma esencialista la sexualidad femenina a la masculina. Las teóricas de la diferencia sexual no se reducen a las fuertes corrientes contemporáneas norteamericanas, incluyen a las italianas de la Librería de Mujeres de Milán y a las feministas francesas lideradas por Luce Irigaray, para quienes la naturaleza humana implica dos, masculina y femenina, que dos son las culturas y los ordenes simbólicos del ser humano y la diferencia sexual está en el orden mismo de las cosas, en un sentido existencial u ontológico.

En las antípodas de este feminismo esencialista — cultural y de la diferencia- ubicamos a Judith Butler, Teresa de Lauretis, Rosi
3) La definición de la prostitución como una práctica tradicional nociva se extendió en 1995 a partir del docu- mento de la ONU titulado Prácticas tradicionales nocivas que afectan la salud de las mujeres y los niños. 
Braidotti, la recientemente fallecida Adrienne Rich, entre otras, quienes, abrevando en el posestructuralismo, la deconstrucción derridiana y una relectura de Lacan y de Foucault, hacen estallar las categorías de género, sexo, deseo, heterosexualidad y homosexualidad. En los 90 , las políticas queer y los planteos posmodernos hicieron saltar por los aires pretendidos monopolios de voces feministas y minorías de todo tipo: transexuales, travestis, lesbianas, negras, chicanas, aborígenes, etc., se alzaron para recuperar como polivalente y coral un espacio inclusivo de todas las mujeres en un mundo globalizado. Nuestra línea de trabajo sobre Diversidad sexual, ciudadanía y derechos humanos se inscribe en la lógica butleriana que asegura que tanto el género como el sexo están social y discursivamente constituidos. "En este sentido, el género no es de ninguna manera una identidad estable (...) es una identidad débilmente constituida en el tiempo: una identidad instituida por una repetición estilizada de actos. El género tiene una apariencia de sustancia, es el resultado performativo que los propios actores han venido a creer y a actuar como creencia" (Butler, 1990:270-282). Por lo tanto, si la identidad de género es el resultado de una repetición estilizada de actos en el tiempo, se puede y se debe subvertir, alterar, modificar. El derecho a la identidad sexual de preferencia es un derecho humano.

Al Programa le preocupa la reproducción del patriarcado en los medios de comunicación y tiene una línea de trabajo en el área. Nuestras reflexiones e investigación nos llevaron a concluir que el sistema de medios neoliberal, global y local es prostibulario, por cuanto despliega una actividad proxeneta, ofrece y vende cuerpos de mujeres y, como consecuencia, los medios son una plataforma que "vende" o reproduce subordinación femenina, que es una forma de violencia que se ejerce sobre las mujeres y que llamamos simbólica. Esta subordinación se realiza en los medios a través de una maniobra doble. Por un lado, las mujeres son invisibilizadas (están excluidas o ausentes) en la esfera público-política de la información y, por el otro, son hipervisibles en el mercado publicitario de prostitución/cuerpos, en la publicidad y el entretenimiento. De esta manera, los medios materializan dominación masculina o poder político androcéntrico/falocéntrico, lo cual establece una condición de causa y efecto al mismo tiempo, con la violencia patriarcal en las instituciones de la sociedad. El feminismo es una estructura de la autoconciencia política de las mujeres $\mathrm{y}$, por lo tanto, reflexiona sobre un conocimiento que es histórico, situado, contingente y, por ende, sin garantías de veracidad, porque nos interroga en el presente y nos enfrenta a la inconmensurabilidad de las diferencias. Son múltiples las diferencias que estructuran a los sujetos y esto nos obliga a pensar en la simultaneidad de efectos sociales, discursivos y simbólicos potencialmente contradictorios que operan en las narrativas que habitamos. Las mujeres pertenecemos a/somos de diferentes clases sociales, razas, etnias, religiones, nacionalidades, edades, modos de vida y preferencias sexuales.
Es por eso que ponemos el acento en el mayor de nuestros logros, el haber crecido acompañadas por la demanda de las mujeres de la sociedad civil. De este modo, nos hemos dejado guiar por la pluralidad misma y la situación concreta de problemas y conflictos de las ciudadanas y ciudadanos. Esta posición política y epistemológica nos compromete, por cierto, con el futuro. En ese sentido, pensar en tiempos de transformaciones nos invita a centrarnos en los procesos y las paradojas, en los fluidos del intercambio y en las múltiples operaciones del poder. Nuestros desafíos a futuro incluyen la conciliación estratégica del feminismo liberal centrado en los derechos de las mujeres, con la explosión de la categoría "mujeres" en una miríada de diferencias y alteridades. La multiculturalidad de los saberes situados y las sexualidades diferentes exigen del feminismo un proyecto político que sea plural y eficaz, con valores modernos y herramientas posestructuralistas, en el marco de una comprensión operativa de las dimensiones materiales y simbólicas, psíquicas y sociales de la dominación masculina. Ha sido éste un largo camino, político, pedagógico y militante. El Programa de Género, Sociedad y Universidad celebra sus primeros diez años y renueva su compromiso por muchos más.

\section{Bibliografía}

Amorós, Celia (2006). Feminismo y Filosofía. Madrid: Síntesis. Barry, Kathleen (1995). The Prostitution of Sexuality. New York: New York University Press.

Butler, Judith (1990). "Actos performativos y constitución del género: un ensayo sobre fenomenología y teoría feminista." En Sue-Ellen Case (ed.). Performing Feminism: Feminist Critical Theory and Theatre. John Hopkins University Press. Gómez Aceibo, Isabel (2003). "Dios en la teología feminista. Estado de la cuestión." Estudios Eclesiásticos 78, nº 304.

Hartmann, Heidi (1979). "The Unhappy Marriage of Marxism and Feminism: Towards a more Progressive Union." Capital \& Class Summer 3, pp. 1-33. Jeffreys, Sheila (2011). La industria de la vagina. La economía política de la comercialización global del sexo. Buenos Aires: Paidós.

Millet, Kate (2010). La política sexual. Madrid: Cátedra.

Valcárcel, Amelia (2004). La Política de las mujeres. Madrid: Cátedra. Young, Iris (1981). "Beyond the Unhappy Marriage: A Critique of the Dual System Theory." En Lydia Sargent (ed.). Women and Revolution. Quebec: Black Rose Books. 